\title{
Usos de las redes sociales digitales para la acción colectiva: el caso de Ni Una Menos
}

\section{Gerardo Caballero}

Pontificia Universidad Católica del Perú gerardo.caballero@pucp.edu.pe

RESUMEN

El siguiente articulo busca mostrar el papel que las redes sociales digitales cumplen en los episodios de movilización y acción colectiva a través de un estudio de caso: la marcha contra la violencia hacia la mujer ocurrida el 13 de agosto de 2016 en Lima y otras ciudades del país, bajo la consigna «Ni Una Menos».

El estudio describe las formas en que las distintas herramientas y servicios de Facebook (actualización de status, messenger, grupos, fanpage) facilitan una serie de procesos indispensables para la acción colectiva: surgimiento de la indignación, activación emocional, deliberación, coordinación, organización y difusión de información.

Asimismo, se muestra que, en caso que surjan tensiones internas en el proceso de movilización, estas se reproducen también en los espacios que brindan las redes sociales digitales ${ }^{l}$.

Palabras clave: redes sociales, acción colectiva, violencia contra la mujer, feminismo, Facebook, Ni Una Menos.

\footnotetext{
$1 \quad$ El presente artículo está elaborado sobre la base de la tesis que el autor elaboró para optar el grado de magíster en Sociología, titulado «Redes sociales y feminismos en la acción colectiva: el caso de 'Ni Una Menos' en el Perú» (Caballero Rojas, 2018). Para la elaboración de este artículo se recogieron los testimonios de siete organizadoras de la marcha, efectuadas entre agosto y setiembre de 2017.
} 


\section{Uses of digital social networks for collective action: the case of «Ni Una Menos»}

\section{ABSTRACT}

The following article seeks to show the role that digital social networks play in the episodes of mobilization and collective action, through a case study: the march against violence against women that took place on August 13, 2016 in Lima and other cities of the country, under the slogan «Ni Una Menos».

The study describes the ways in which the different tools and services of Facebook (status update, messenger, groups, fanpage) facilitate a series of indispensable processes for collective action: emergence of outrage, emotional activation, deliberation, coordination, organization and dissemination of information.

It also shows that in the event that internal tensions arise in the process of mobilization, these are also reproduced in the spaces provided by digital social networks.

Keywords: social networks, collective action, violence against women, feminism, Facebook, Ni Una Menos. 


\section{INTRODUCCIÓN}

El 13 de agosto de 2016 se llevó a cabo en Lima una movilización tan multitudinaria que algunos diarios de la capital no dudaron en calificarla de histórica ${ }^{2}$. «Nunca tantos marcharon en defensa de la mujer», precisaba La República al día siguiente en su portada. Según sus propios cálculos, la manifestación —convocada como respuesta a dos sentencias benignas en casos de violencia de género- había llegado a movilizar a unas 150000 personas y había sido «la más grande de la historia» (Chinchay y Cortijo, 2016).

Los estudios sobre este tipo de fenómenos en América Latina se han centrado en el análisis de sus manifestaciones artísticas y audiovisuales (Mujeres Grabando Resistencia, 2018; Rovetto, 2015), sus causas y repercusiones políticas y culturales (Bard Wigdor y Artazo, 2015), sus dinámicas internas de movilización social (Castro, 2018) y su contribución a la formación de la violencia como problema público (Cabral y Acacio, 2016). En este artículo nos centraremos en el estudio de las formas en que la red social digital Facebook facilitó el surgimiento de la acción de protesta.

Y es que, como afirma Manuel Castells (2012), las redes sociales digitales basadas en internet y en plataformas inalámbricas son herramientas decisivas para movilizar, organizar, deliberar, coordinar y decidir, y facilitan un proceso de comunicación a través del cual se comparten los acontecimientos y emociones. Cuanto más rápido e interactivo sea este proceso, más probable es que surja la acción colectiva (Castells, 2012, p. 32).

\section{ACCIÓN COLECTIVA Y REDES SOCIALES}

Desde las ciencias sociales, lo ocurrido el 13 de agosto de 2016 (13A) en las calles de Lima fue un episodio de acción colectiva, que es aquello que «se pone

2 Así lo hicieron los diarios La República, Perú.21 y El Comercio en sus respectivas portadas del 14 de agosto de 2016. 
de manifiesto cuando los ciudadanos corrientes - con frecuencia en alianza con ciudadanos más influyentes y con cambios en el ambiente general- unen sus fuerzas para enfrentarse a las élites, a las autoridades y a sus antagonistas sociales» (Tarrow, 2012, p. 31).

El 13A tuvo una consigna a manera de nombre: «Ni Una Menos». Fue una movilización nacional de rechazo a la violencia contra las mujeres. Decenas de miles de manifestantes marcharon en Lima hacia el frontis del Palacio de Justicia, sede emblemática del Poder Judicial peruano. El recorrido elegido no era una casualidad.

Casi un mes antes, el 14 de julio de 2016, la Corte Superior de Justicia de Ayacucho había sentenciado a Adriano Pozo Arias a un año de prisión suspendida por haber golpeado salvajemente a su ex pareja, Arlette Contreras, en julio de 2015. Un día después, el 15 de julio de 2016, la Primera Sala para Reos en Cárcel de la Corte Superior de Justicia de Lima había condenado a cuatro años de prisión suspendida a Rony García, quien en 2012 había agredido de manera brutal a Lizeth Rosario Socia Guillén, conocida como «Lady Guillén». En ambos casos, el fallo judicial representó la excarcelación de los agresores. Fue entonces cuando un grupo de mujeres decidió organizarse para llevar a cabo una movilización nacional como respuesta a la sensación de impunidad que el sistema de justicia generaba.

\section{LA PROPAGACIÓN DE LA INDIGNACIÓN}

En su casa del distrito de Barranco, Jimena Ledgard, una joven feminista, egresada de filosofía de la Pontificia Universidad Católica del Perú (PUCP), veía con estupor la noticia sobre el fallo de Arlette Contreras. Frente a la pantalla, no conseguía entender cómo los jueces habían tomado esa decisión cuando existía un registro de la terrible agresión.

Las imágenes correspondían a la cámara de seguridad del hotel Las Terrazas, en Ayacucho, al cual Arlette Contreras y Adriano Pozo habían llegado la madrugada del 7 de julio de 2015. En ellas se ve a la mujer salir corriendo de la habitación donde se encontraba ${ }^{3}$. Consigue llegar a la recepción, pero Pozo la alcanza. En el forcejeo, Arlette cae al suelo y entonces es arrastrada del cabello por su agresor, imagen que se hizo tan icónica que sirvió de referente para caricaturistas políticos, tal como se puede ver en la figura 1 .

\footnotetext{
3 Para más detalles sobre lo ocurrido en el hotel Las Terrazas, ver: Latina.pe, 2015.
} 
Viendo la noticia, Jimena se puso a llorar de impotencia. La embargaba la indignación. «Ese día, de verdad, yo quería romper todo a mi alrededor — relata Jimena- Creo que pocas veces en mi vida he sentido tanta rabia como en ese momento» ${ }^{4}$.

Según Manuel Castells (2012), el poder de las imágenes es primordial en los episodios de acción colectiva. Ahí donde la chispa de indignación ha estado relacionada con un acontecimiento concreto, siempre ha habido imágenes movilizadoras que han despertado la indignación y han generado los llamados a la acción.

\section{Figura 1}
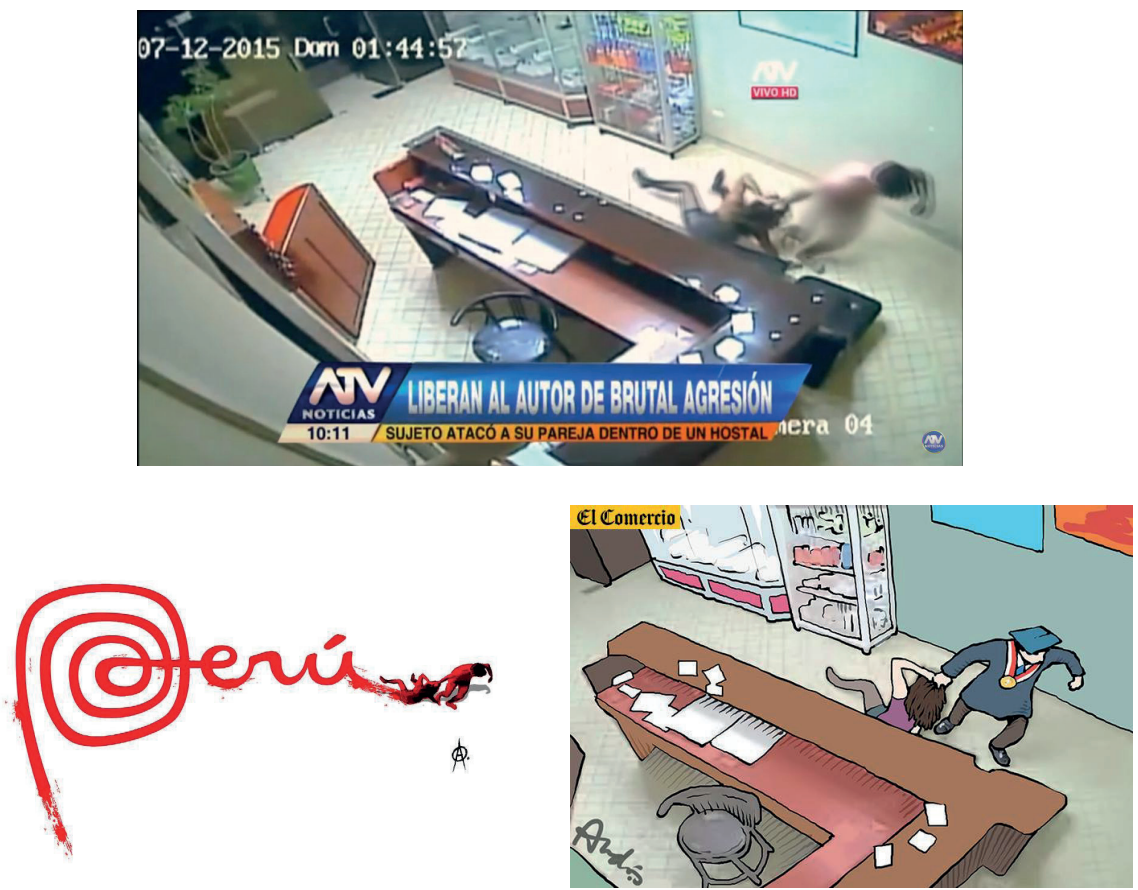

Arriba: captura de pantalla sobre noticia sobre fallo en el caso de Arlette Contreras, en ATV. Abajo izquierda: viñeta de Álvaro Portales. Abajo derecha: viñeta de Andrés Edery, para El Comercio.

En este estado, Jimena empezó a escribir en su cuenta de Facebook un extenso post, que es como se llama comúnmente a las actualizaciones de estado (status update). Esta es una de las formas más usuales de usar esta red social, mediante

$4 \quad$ Entrevista a Jimena Ledgard, realizada el 12 de setiembre de 2017. 
la cual los usuarios comparten algún tipo de contenido. Este puede incluir texto, un enlace a una página web o una foto. Su apariencia es la que puede verse en la figura 2.

\title{
Figura 2
}

\begin{abstract}
(2) Jimena Ledgard
16 de julio de 2016 .

Hace un año, Cindy Contreras estaba en un hotel con su pareja que había llegado de una fiesta, borracho, a encontrarse con ella. En el cuarto, ella intentó terminar la relación y, cuando el quiso tener sexo con ella y ella se rehusó, la golpeó, amenazó de muerte y ahorcó. Las venas de sus ojos se reventaron por la presión contra su cuello. Ella pidió a gritos ayuda, pero cuando el encargado del hotel subió a ver qué pasaba, no hubo respuesta. Cindy se había desmayado, no sabe por cuánto tiempo. Cuando recuperó la consciencia, vio a su pareja haciendo pila en el baño, así que se levantó y huyó. Esa es la parte de la historia que sucedió tras puertas cerradas, como sucede todo el tiempo en todo el mundo. Como posiblemente esté sucediendo en este instante mucho más cerca de lo que imaginas. Como tal vez le suceda a alguna amiga tuya, familiar o colega del trabajo sin que tú tengas idea.
\end{abstract}

Lo que siguió luego lo sabemos gracias a las cámaras de seguridad del hotel. Adriano Pozo, así se llama ese hombre, la golpeó y arrastró por el suelo, agarrada del pelo como si fuera un animal que llevas al matadero. Todos hemos visto esas imágenes. Cindy intentando huir y Adriano desnudo y enloquecido persiguiéndola y golpeándola.

Antes de ayer, un jurado, crucifijo en mesa, dejó a Adriano Pozo en libertad. 5000 soles, un año de prisión suspendida por "lesiones leves" y a su casa. Esos miserables, por cierto, también tienen nombre: María Pacheco Neyra,

Jimena acompañó su publicación con capturas de pantalla de la agresión que sufrió Arlette Contreras. El texto proseguía con un llamado a la acción colectiva:

Antes de ayer, un jurado, crucifijo en mesa, dejó a Adriano Pozo en libertad. 5000 soles, un año de prisión suspendida por «lesiones leves» y a su casa. Esos miserables, por cierto, también tienen nombre: María Pacheco Neyra, Nazario Turpo Coapaza y Edgar Sauñe de la Cruz. Grábense esos nombres. Ellos serán responsables si Pozo vuelve a ponerle un dedo encima, hoy, mañana o en un diez años [sic] a Cindy Contreras o a cualquier otra mujer. Ellos son los responsables de que hoy una mujer más deba vivir escondida y aterrada por su vida.

Si un video en el que se ve cómo arrastran a una mujer por el suelo no nos protege, ¿entonces qué nos queda?, ¿qué nos cuida?, ¿quién vela por nosotras?, ¿dónde mierda está el Estado al que tanto se supone le debemos? Si un 
video en el que nos golpean circul [sic] por todos los canales de televisión del país y aun así no pasa nada, ¿qué pasa cuando nos golpean, cuando nos violan, cuando nos amenazan en privado? Nos están matando y nadie hace nada.

Que la historia registre esa vergüenza y a sus culpables, y que hoy sea un llamado a la acción. Nadie nos va ayudar, necesitamos cuidarnos nosotras. ¿Cuándo tomamos la calle, hermanas?, ¿cuándo decimos nosotras «ni una menos»»? (Ledgard, 2016).

La publicación se viralizó. Al 3 de octubre de 2017, 4118 usuarios habían clicado los botones de «Me gusta», «Me enfada», «Me entristece» $\mathrm{o}$ «Me asombra», que son formas de adhesión que Facebook contempla. Asimismo, esta actualización de estado había sido compartida 3131 veces y había recibido 163 comentarios.

Y así como se fue difundiendo la publicación de Jimena, también lo hizo la indignación. Precisamente es este sentimiento el que las organizadoras del 13A mencionan más frecuentemente cuando relatan el episodio del fallo judicial del caso de Arlette Contreras. «Luego de lo de Arlette, de ver el video donde la arrastran en el hotel, es como una conjunción de voluntades: varias mujeres indignadas por lo que le había pasado a Arlette comienzan a manifestarse por las redes para hacer algo», comenta Verónica Ferrari, activista feminista y ex presidenta del Movimiento Homosexual de Lima (MHOL) 5 .

Si bien es cierto que determinado contexto nacional o regional puede alentar la aparición de episodios de acción colectiva, en casos como el que hemos analizado es necesaria una chispa que encienda la indignación. En este caso, la decisión que tomó la Corte Superior de Justicia de Ayacucho, a pesar de las imágenes de la golpiza que sufrió Arlette Contreras, fue el detonante, pues evidenció la incapacidad de las instituciones del Estado para castigar la violencia contra la mujer.

Aquel sábado 16 de julio, en otro lugar de Lima, Kathe Soto, socióloga de la Universidad Nacional Federico Villarreal y activista feminista de Carabayllo, también volcaba su indignación en el Facebook por la noticia de Arlette Contreras. En su cuenta en esa red social, Kathe también publicó una actualización de estado que era un llamado a la movilización, tal como se puede leer en la figura 3:

$5 \quad$ Entrevista a Verónica Ferrari, realizada el 8 de agosto de 2017. 


\section{Figura 3}

(2)

Kathe Soto ha añadido 2 fotos nuevas.

16 de julio de 2016 .

¿Y entonces qué ?

- Un criminal más está libre. Un tipo que intentó asesinar a una mujer en

Ayacucho, arrastrándola de los cabellos y golpeándola para violarla.

¿Y entonces qué?

-Entre lágrimas ella dice que tiene miedo por su vida, que no cree en lo que llaman "justicia".

¿Y entonces ahora, qué haremos compañeras?

- ¡Qué haremos para que ninguna de nuestras compañeras en Ayacucho, Lima y todo el Perú sepa que no estamos solas! ¡Para que nos dejen de caer lágrimas de indignación y cólera! ¡Para dejarle bien claro a todos los machos que jamás estaremos calladas, porque nos tocan a una, nos tocan a todas!

¿Y entonces? ¿Nos vamos a las calles?

En este caso, es oportuno precisar a qué nos referimos cuando decimos activista. Tal como señalan Neumayer y Svensson (2016), consideramos activismo a una forma de participación política externa a las instituciones de la democracia representativa y consiste en la participación en actividades que tienen el propósito explícito de influir sobre quienes toman las decisiones que afectan al público y sobre la sociedad en su conjunto. Asimismo, consideramos que los activistas cumplen en los movimientos sociales un papel similar al que - de acuerdo con Piñeiro y Rosenblatt (2017) — realizan los militantes en las organizaciones políticas: se involucran de manera voluntaria en la acción política, operan en campaña y en tiempo no electoral y están dispuestos a invertir recursos - dinero y, sobre todo, tiempo- en sostener la organización.

Y fueron precisamente activistas quienes, en su mayoría, vieron la publicación de Kathe Soto aquel sábado 16 de julio. Su actualización de estatus tuvo un alcance mucho menor que la de Jimena Ledgard. Al 3 de octubre de 2017, registraba solo 51 reacciones, 22 comentarios y había sido compartido apenas una vez.

\section{EL FACEBOOK Y LA CONEXIÓN DE LOS CÍRCULOS SOCIALES}

Pero había otra gran diferencia entre ambas publicaciones. Tal como anota Kathe Soto, entre quienes comentaron la publicación de Jimena Ledgard no había 
«ninguna compañera feminista». En cambio: «en el post que yo tenía [quienes comentaban] eran todas las compañeras que por lo menos nos conocemos de la campaña 'Déjala Decidir' del Colectivo 25 de Noviembre, o sea las clásicas feministas que armamos todas estas marchas de Canto a la Vida $»^{6}$. Kathe marca así la distinción entre las feministas que se encuentran dentro del activismo movimientista y quienes no.

Esta distinción se manifiesta también en los comentarios que recibieron las publicaciones tanto de Jimena como de Kathe. En los que aparecen en el post de esta última, por ejemplo, se aprecia el uso del término «compañeras» (o «compas»), con el que las activistas llaman a quienes reconocen como integrantes del movimiento feminista. En cambio, en la publicación de Jimena Ledgard, las expresiones que las usuarias empleaban para referirse a sus pares eran otras, tales como «amigas», «chicas» o «mujeres».

Tanto en el ciberespacio como en la vida real, Jimena y Kathe se desenvolvían en círculos sociales muy distintos. La teoría de redes sociales nos dice que, si viéramos el mundo como un interminable entramado de relaciones sociales, podríamos encontrar lo que Kadushin (2013) llama los «círculos sociales», que son redes que normalmente se construyen sobre la base de unos intereses comunes o están vinculados con estatus, roles y organizaciones: son regiones del mundo social donde es posible encontrar más relaciones.

$\mathrm{Y}$ esto se produce porque las personas tenemos una tendencia - consciente o inconsciente - a asociarnos con personas que se parecen a nosotros. Es lo que se llama homofilia, lo cual nos lleva a buscar a aquellas personas que comparten nuestros intereses, historias y sueños (Christakis y Fowler, 2010).

Esta configuración de las redes hace que, así como hay círculos sociales, encontremos también «agujeros estructurales», que son situaciones en las que un nodo (una persona) conecta a individuos que están conectados entre sí mismos, pero que, sin la presencia de ese nodo, no tendrían conexión unos con otros (Kadushin, 2013). Estos individuos cumplen el papel de puente, que son los nodos que consiguen unir grupos (o conglomerados de relaciones) poco conectados entre sí (Maya Jariego, 2016).

Tal era el caso de los círculos sociales de Jimena y de Kathe, quienes prácticamente no tenían ningún amigo o contacto en común en Facebook, con excepción de unas pocas usuarias que funcionaron como puentes y permitieron unir estas redes hasta entonces desconectadas.

6 Entrevista a Kathe Soto, realizada el 15 de setiembre de 2017. 
Ese era el caso de Micaela Távara, performer y activista del movimiento feminista (o «artivista»). «Jimena y yo — explica Micaela—, si bien es cierto sí somos amigas, pero digamos somos también como de espacios bien diferentes» ${ }^{7}$. No obstante, las unió su inclinación por el feminismo: se habían conocido en 2015, cuando participaron en un conversatorio realizado en el marco de la campaña «Déjala Decidir».

Otra persona que funcionó como puente fue Q'antu Madueño, activista del movimiento feminista a la que Kathe había conocido en el Centro de la Mujer Peruana Flora Tristán, una organización no gubernamental (ONG) muy importante en el movimiento feminista del Perú. Q'antu fue una de las primeras activistas que vio el post de Jimena Ledgard y lo que hizo fue etiquetar a colectivos feministas en los comentarios.

El tag o etiqueta es en Facebook un recurso que convierte el nombre de un usuario o de una fanpage en un enlace hacia esa página. La creación de un tag envía además al usuario etiquetado una notificación: «Te han mencionado en un comentario». De esta manera, el usuario etiquetado puede involucrarse en una publicación de la cual no estaba al tanto, sea esta de un contacto suyo o no.

Y eso fue lo que hizo Q'antu Madueño cuando colocó en la publicación de Kathe un comentario en el que etiquetó a Jimena: «Jimena Ledgard también está moviendo esta iniciativa, hay que comunicarse con ella».

\section{EL FACEBOOK MESSENGER COMO HERRAMIENTA PARA LA COORDINACIÓN}

Aquel sábado 16 de julio, Micaela Távara fue otra de las que vio el post de Jimena y decidió comunicarse con ella a través del chat de Facebook para empezar a planear algún tipo de acción. Por su parte, en su publicación de Facebook, Kathe Soto empezaba a recibir de sus «compañeras» comentarios que la alentaban a organizar alguna movilización, y ella decidió etiquetar a colectivos feministas para interesarlos en lo que iban a planificar.

Fue entonces cuando Kathe inició un chat en Facebook con sus «compañeras». En ese chat discutieron qué acción llevarían a cabo como protesta ante el fallo del caso de Arlette Contreras.

El Facebook Messenger, comúnmente llamado «chat del Facebook», es la aplicación de mensajería instantánea de esta red social. Tiene la ventaja de

7 Entrevista a Micaela Távara, realizada el 2 de octubre de 2017. 
que no solo puede ser usado por dos usuarios, sino que eventualmente pueden agregar a otro usuario a la conversación. Y a otro. Y a otro. Y a otro más. Hasta un máximo de 250.

En el chat que Kathe Soto y sus compañeras habían creado, decidieron hacer una intervención, que es un tipo de acción colectiva rápida y pequeña que busca modificar (o intervenir) algún espacio público. Y así lo hicieron la madrugada del lunes 18 de julio: pintaron en la pared del Ministerio Público «Poder Judicial feminicida».

A este mismo chat de Facebook habían sido agregadas Micaela Távara y Jimena Ledgard, pero ambas habían optado por no participar en la intervención en la sede judicial.

En este mismo chat, desde el día en que fue creado, el mismo sábado 16 de julio, Jimena y Micaela habían empezado a agregar contactos. Esta última había añadido a sus compañeras activistas, mientras que Jimena había añadido contactos suyos de otros espacios. Una de ellas era Natalia Iguiñiz.

Jimena y Natalia no eran amigas, pero estaban conectadas a través del Facebook, pues habían compartido una mesa en un conversatorio organizado por una ONG feminista ${ }^{8}$. Según el testimonio de las entrevistadas, ambas pasaron a ser muy unidas y a ocupar un papel central en la organización de la marcha del 13A.

Otra de las personas que fue añadida al chat fue Elizabeth Vallejos, socióloga, docente de la PUCP y fundadora del colectivo «Paremos el Acoso Callejero». La relación que Elizabeth tenía con Jimena y Natalia hasta antes del 16 de julio de 2016 permite ilustrar cómo las redes sociales sirven para los fines de movilización:

Cuando yo estaba en «Paremos [el Acoso Callejero]», yo la he visto [a Jimena] en ese espacio, donde se estaba organizando «Un Billón de Pie» ${ }^{9}$. Y recuerdo haberle hablado ahí. Pero nuestra comunicación en general era en Facebook. [...] No tengo el recuerdo de haber estado físicamente en algún espacio con ella, pero sí tengo el recuerdo de haber comentado mucho en sus posts y ella en los míos. Y a Natalia recuerdo haberla visto [...] en una reunión de la universidad, cuando se estaba haciendo una encuesta de género. Esa es la única vez en mi vida que la había visto [...], pero también la tenía en Facebook, como todas las activistas se suelen tener en Facebook [...], no era porque éramos amigas ni nada. Pero sí nos comentábamos mucho, recuerdo ${ }^{10}$.

\footnotetext{
8 Entrevista a Jimena Ledgard, realizada el 12 de setiembre de 2017.

9 «Un Billón de Pie» es el nombre de una campaña en contra de la violencia hacia la mujer que tuvo como emblema a varios actores conocidos y que se llevó a cabo en 2015.

10 Entrevista a Elizabeth Vallejo, realizada vía Skype el 17 de setiembre de 2017.
} 
Este testimonio muestra que las relaciones en el mundo virtual no se nutren necesariamente de una amistad en el mundo real, sino de otras formas de interacción, como comentarios y likes, que son formas mediante las cuales un usuario expresa su interés por una publicación. De esta manera, las redes sociales digitales nos inducen a interactuar más frecuentemente con aquellas personas que piensan como nosotros o comparten nuestros intereses. Y esto nos lleva a suponer que en las redes sociales de internet se produce también la homofilia.

El chat creado ese sábado 16 de julio empezó entonces a crecer a un ritmo inesperado: «Pasó de cinco a diez en un minuto — cuenta Natalia Iguiñiz-y pasó de diez a cincuenta en cinco minutos» ${ }^{11}$. Este espacio sumó a tantas personas que acabó incluyendo en él a mujeres adscritas a diversas vertientes del feminismo.

Con «vertientes del feminismo» queremos referimos a las corrientes que Vargas Valente (2008) identifica en el movimiento de mujeres en el Perú, y que son tres: (i) la vertiente feminista, aquella cuyos esfuerzos están dirigidos de manera explícita a identificar y denunciar la existencia de un sistema de sexo-género que subordina a las mujeres; (ii) la vertiente popular, que está integrada en su mayoría por mujeres que buscan satisfacer necesidades y demandas que surgen de sus roles tradicionales, a los que han dado un contenido más público, y (iii) la vertiente política, que es la de los espacios públicos tradicionales, como partidos, sindicatos y asociaciones. Las mujeres de esta vertiente buscan modificar estos espacios y abrir otros nuevos para lograr una mayor participación y luchan por un reconocimiento formal y más público de los derechos femeninos.

En ese espacio virtual concurrieron Carla Díaz, activista feminista del Centro de la Mujer Peruana Flora Tristán y comunicadora de la Universidad Nacional Federico Villarreal; Verónica Ferrari, activista feminista, ex presidenta del Movimiento Homosexual de Lima y lingüista de la Universidad Nacional Mayor de San Marcos; Claudia Salazar Jiménez, escritora radicada en Nueva York; María Angélica 'Nani' Pease, doctora en psicología y profesora de la PUCP; María Ysabel Cedano, abogada, directora del Estudio para la Defensa de los Derechos de la Mujer (Demus); Amanda Meza, periodista y activista; Mariel Távara, activista feminista y prima de Micaela; Rocío Silva Santisteban, literata, docente universitaria y ex directora ejecutiva de la Coordinadora Nacional de Derechos Humanos; Johana Asurza, quien había trabajado en la mencionada ONG bajo su dirección como encargada de los asuntos de mujeres y pueblos indígenas, y Sandra de la Cruz, activista del feminismo político e integrante del Frente Juvenil

11 Entrevista a Natalia Iguiñiz, realizada el 16 de agosto de 2017. 
de Izquierda, quien había participado en la organización de las movilizaciones contra la «Ley Pulpín» y la candidatura presidencial de Keiko Fujimori en 2016.

En ese chat de Facebook, las participantes propusieron llevar a cabo una reunión de coordinación. Jimena ofreció su casa de Barranco y allí se produjo el primer encuentro. «Debemos haber sido unas veinte mujeres o dieciocho mujeres, de las cuales no conocía casi a ninguna», recuerda la anfitriona, lo cual muestra cómo es que las redes sociales digitales permiten que se formen ciertos tipos de relación ahí donde no había mayor vinculación en el mundo real ${ }^{12}$.

\section{UN GRUPO DE FACEBOOK COMO ESPACIO PARA LA ACTIVACIÓN EMOCIONAL}

La coordinación de la movilización excedió las capacidades del chat de Facebook. En primer lugar, porque eran muchas las usuarias que participaban y, en segundo lugar, porque lo hacían con mucha frecuencia. Lo que sucedió es que, cuando una de ellas quería hacer un comentario sobre una intervención anterior, se hacía prácticamente imposible saber a quién estaba respondiendo. La solución planteada ante este desorden fue crear un grupo de Facebook, que es un espacio creado y formado en la red social para que distintos usuarios, con intereses comunes o un propósito particular, compartan conocimiento o información (Carbellido Monzó, 2018).

Fue así como las mujeres incluidas en el chat, que ya eran cerca de $\operatorname{cien}^{13}$, decidieron crear el grupo cerrado de Facebook «Ni Una Menos: Movilización Nacional Ya» (NUM-MNY). Ese grupo se creó el domingo 17 y su finalidad era constituirse en un espacio para la coordinación y organización de una marcha nacional. Jimena y Natalia se convirtieron en las administradoras del grupo.

Sin embargo, es necesario tener en cuenta que, aunque fue creado como un grupo cerrado, NUM-MNY no era propiamente un espacio cerrado: cualquiera de sus integrantes - casi todas mujeres - podía agregar a otros usuarios o usuarias. Como consecuencia de ello, el número de miembros del grupo aumentó de manera sorprendente en los primeros días.

Pronto, la naturaleza del grupo cambió cuando la artista María Elena Alvarado Boggio (conocida como Mari Gho) escribió que, para decir «ni una menos», era necesario salir del clóset de la violencia y compartió una experiencia propia verdaderamente traumática. «Mari Gho fue la primera que en ese grupo cerrado

\footnotetext{
12 Entrevista a Jimena Ledgard, realizada el 12 de setiembre de 2017.
}

13 Entrevista a Jimena Ledgard, realizada el 12 de setiembre de 2017. 
puso su propio testimonio de violación — recuerda Natalia- - Y eso destapó la olla. Fue como empezaron los testimonios por montones, una cosa de locos» ${ }^{14}$.

Los testimonios que empezaron a revelarse relataban frecuentemente episodios de violencia sexual. Las mujeres decían que habían guardado silencio debido a la culpa que habían experimentado a pesar de ser ellas las víctimas. Sin embargo - expresaban-, habían encontrado en esta experiencia colectiva generada por NUM-MNY el coraje para dar a conocer sus testimonios de violencia, además de lo cual hacían un llamado a la movilización ${ }^{15}$.

La literatura sobre los movimientos sociales en red (Castells, 2012) nos dice que para que se produzca un episodio de acción colectiva es necesario (aunque no suficiente) que exista un proceso de activación emocional, que es un proceso de comunicación en el cual la ira permite superar la ansiedad que el miedo ha desencadenado. Para que haya esta activación emocional, indica Castells, la activación de los individuos debe conectar con la de otros individuos en un proceso de comunicación. Y este proceso tiene dos requisitos: de un lado, la consonancia cognitiva entre emisores y receptores del mensaje y, de otro lado, un canal de comunicación eficaz. Y es así como funciona:

La empatía en el proceso de comunicación está determinada por experiencias similares a las que motivaron el estallido emocional original. En concreto: si muchos individuos se sienten humillados, explotados, ignorados o mal representados, estarán dispuestos a transformar su ira en acción en cuanto superen el miedo. Este miedo lo superan mediante la manifestación extrema de la ira en forma de indignación cuando tienen noticia de que alguien con quien se identifican ha sufrido algo insoportable. Esta identificación se consigue compartiendo sentimientos en una forma de compañerismo que se crea en el proceso de comunicación. La segunda condición para que las experiencias individuales se conecten y formen un movimiento es, por tanto, la existencia de un proceso de comunicación que propague los acontecimientos y las emociones asociadas a las mismas. Cuanto más rápido e interactivo sea el proceso de comunicación más probable es que se forme un proceso de acción colectiva, arraigado en la indignación, impulsado por el entusiasmo y motivado por la esperanza (Castells, 2012, pp. 31-32).

El grupo de Facebook NUM-MNY fue precisamente el espacio virtual en el que se llevó a cabo este proceso de comunicación. Y, como si se tratara de

14 Entrevista a Natalia Iguiñiz, realizada el 16 de agosto de 2017.

15 Algunos de los testimonios fueron publicados con autorización de las víctimas en el portal Utero.pe (ver: Grados, 2016). 
una espiral creciente, mientras cada vez más integrantes del grupo se atrevían a compartir sus testimonios de violencia, muchas más les expresaban su solidaridad a través de comentarios y reacciones. Y esa experiencia de revelación y de solidaridad motivaba a más mujeres a dar a conocer sus propias experiencias.

En esos días de julio de 2016, NUM-MNY recibía entre 5000 y 10000 nuevos miembros cada día, y llegó casi a $70000^{16}$. Esto hizo que muchas de sus integrantes tomaran conciencia de las dimensiones de la violencia de género, pues descubrían que sus amigas, hermanas, colegas, primas, en fin, mujeres que conocían, habían padecido cruentos episodios de violencia. «Tú podías leer historias terroríficas de violencia sexual espantosa de tus amigas a los cinco años, a los seis años, a los siete años — comenta Verónica Ferrari-. Y eran personas que estaban a tu lado, y no sabías lo que estaba pasando. [...] Y eso movilizó muchísimo, movilizó un montón» ${ }^{17}$.

El grupo creció tanto que empezaron a sumarse también personas (mujeres y hombres) que no compartían los ideales feministas de sus promotoras, así como otras que tenían expresiones misóginas, homofóbicas y lesbofóbicas. También aparecieron quienes condenaban la despenalización del aborto, una de las principales banderas del movimiento feminista en el Perú. Las administradoras del grupo notaron que habían empezado a ingresar hombres con el propósito de averiguar si sus parejas o ex parejas habían revelado algún episodio de violencia que los comprometiera. Esto las llevó a realizar una especie de purga de hombres en este grupo de Facebook. Con esta medida, el número de integrantes fue disminuyendo poco a poco.

Más tarde, NUM-MNY pasaría a ser grupo secreto: es decir, nadie podía sumarse por cuenta propia a este espacio ni tampoco solicitar ser incorporado. Debía ser invitado por alguien que ya era miembro ${ }^{18}$.

$\mathrm{Y}$ en vista de que este grupo de Facebook no cumplía con los fines para los cuales había sido creado (es decir, la coordinación de acciones para el 13A), las impulsoras de la marcha optaron por volver a usar el chat de Facebook para coordinar la movilización. Sin embargo, NUM-MNY había hecho un trabajo valiosísimo para la acción colectiva.

\footnotetext{
16 Entrevista a Natalia Iguiñiz, realizada el 16 de agosto de 2017.

17 Entrevista a Verónica Ferrari, realizada el 8 de agosto de 2017.

18 En agosto de 2017, Natalia Iguiñiz estimaba que el número de integrantes oscilaba entre 55000 y 60 000, de las cuales casi el 99\% eran mujeres.
} 


\section{EL FANPAGE: UNA HERRAMIENTA DE DIFUSIÓN PARA LAACCIÓN COLECTIVA}

La primera reunión para empezar a coordinar las acciones de movilización se produjo el lunes 18 de julio de 2016 en casa de Jimena Ledgard. Era un grupo bastante variopinto: había activistas, artistas plásticas, literatas, investigadoras, profesoras universitarias, representantes de colectivos feministas. «Era una reunión realmente bien variada — señala Elizabeth Vallejo-. Había gente de varios rangos de edad, y también de varios perfiles. El perfil común era que todas estaban en el tema de violencia de género y todas eran más o menos activistas» ${ }^{19}$.

En aquella reunión se discutieron varios puntos: (i) el nombre de la movilización; (ii) la plataforma de demanda; (iii) la fecha para la marcha; (iv) el punto donde acabaría el recorrido, y (v) la creación de una fanpage de Facebook para la movilización.

Las páginas de Facebook o fanpage están pensadas para que las marcas, empresas, organizaciones y personajes públicos puedan formar parte de Facebook, pero cualquier persona con una cuenta puede crear una página o ayudar a administrarla (Facebook, 2019). El objetivo es mantener informada a la comunidad de usuarios que deciden seguir la página.

Para elegir el nombre del fanpage de la movilización, hicieron una especie de encuesta virtual utilizando el grupo NUM-MNY. El nombre ganador fue: «Ni Una Menos: Tocan a una, tocan a todas» (NUM-TAUTAT), el cual tiene un claro sentido de solidaridad o de sororidad, como las feministas llaman a las relaciones de solidaridad que hay entre mujeres.

A una de las asistentes, la artista Diana Solís, le encargaron el diseño del afiche para la movilización. Y fue así como al día siguiente, el martes 19 de julio, se publicó en la recién creada fanpage NUM-TAUTAT el arte que aparece en la figura 4.

El arte de la figura 4 no se difundió solo, sino que fue acompañado de un mensaje que buscaba ilustrar la dimensión de la violencia de género:

19 Entrevista a Elizabeth Vallejo, realizada vía Skype el 17 de setiembre de 2017. 
Figura 4

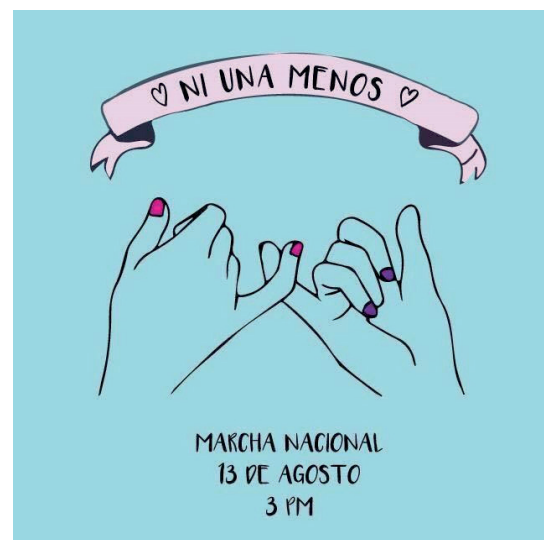

Fuente: Ni Una Menos Perú: tocan a una, tocan a todas.

Todas somos Cindy Contreras ${ }^{20}$. Todas somos Lady Guillén ${ }^{21}$. Todas somos Zuleimy Sánchez ${ }^{22}$. Todas somos la niña a la que su papá toca cada noche. Todas somos la adolescente violada por su tío. Todas somos la mujer a la que su novio agarró a golpes. Todos somos la chica con el ojo reventado y la ropa hecha jirones a la que le preguntaron en la comisaría «qué había hecho» para provocarlo. Todas somos Ayme Pillaca, asesinada por ayudar a una niña de quince años a huir de una red de trata. Todas somos las más de 2074 mujeres esterilizadas, todas somos Manta y Vilca ${ }^{23}$. Tocan a una y nos tocan a todas, y por eso este sábado 13 de agosto, nos movilizamos.

Esta publicación de Facebook tuvo bastante alcance. Al 11 de octubre de 2017, había sido compartida 10009 veces, tenía 9015 reacciones y había recibido 626 comentarios.

20 En ese entonces, Arlette Contreras era conocida como Cindy Contreras.

21 El lunes 18 de julio, se supo que la Primera Sala para Reos en Cárcel de la Corte Superior de Justicia de Lima había condenado a cuatro años de prisión suspendida a Rony García, quien en 2012 había golpeado brutalmente a Lizeth Rosario Socia Guillén, conocida como Lady Guillén. Como sucedió con el agresor de Arlette Contreras, ello también implicó su excarcelación, y el caso de Lady Guillén se volvió emblemático.

22 Zuleimy Sánchez era una adolescente trans de catorce años que fue asesinada a fines de mayo de 2016 de cuatro balazos en la ciudad de Trujillo.

23 Manta y Vilca es el nombre de un caso judicial en el cual son procesados catorce militares por violar campesinas en localidades de Huancavelica cercanas a bases antisubversivas entre 1984 y 1988. 
Ahora bien, para entender la importancia de esta herramienta, es bueno tener en cuenta que la acción colectiva requiere la existencia de capital social, que son recursos que pueden constituir una ventaja (Ostrom, Ahn y Olivares, 2003). Según Nan Lin (2002), las ciber-redes $^{24}$ —es decir, las redes sociales formadas en el ciberespacio y específicamente en la internet - son también una forma de capital social: trasladan recursos como la información y proveen caminos para intercambios y posible formación de colectividades. Las conexiones virtuales de las ciber-redes permiten a los usuarios conectarse con otros con pocas limitaciones de tiempo y espacio (Lin, 2002).

El fanpage NUM-TAUTAT se convirtió en un recurso muy apreciado para la acción colectiva, en la medida que permitía difundir las acciones de organización de la marcha, poner temas en agenda y elaborar discursos alternativos a los que aparecían en los medios de comunicación tradicionales. En poco tiempo, la página alcanzó un número de seguidores inesperadamente alto, lo que le permitía tener un alcance mayor en cada una de las publicaciones. Para noviembre de 2017, NUMTAUTAT se había convertido en la fanpage de un grupo, colectivo u organización feminista peruana con más seguidores. Esto puede apreciarse en el gráfico 1.

Un fanpage de estas características es, entonces, una ciber-red que permite trasladar recursos, como información u opiniones, y facilita las conexiones virtuales entre los usuarios de Facebook que sean ajenos a las redes tradicionalmente feministas. NUM-TAUTAT permitió a las organizadoras del 13A difundir al público en general información sobre la organización de la marcha y compartir con ellos contenidos de interés sobre violencia de género. Esto es lo que convierte a esta fanpage en un poderoso capital social para la acción colectiva.

Como fue Jimena Ledgard quien creó la fanpage en aquella primera reunión en su casa, pasó a ser ella la administradora de la página. Pero, además, había editoras, entre las que se encontraban Natalia Iguiñiz, Dania Chávez, Verónica Ferrari y Amanda Meza, quienes formaron una especie de comisión de comunicación.

\section{LAS DISCREPANCIAS ONLINE}

Algunas de las mujeres que no acudieron a la primera reunión del lunes 18 de julio en casa de Jimena Ledgard habían decidido no ir porque consideraban que ese no era el lugar adecuado para organizar una movilización en favor de las mujeres. Chats y grupos de Facebook de colectivos feministas se convirtieron en espacios en los que se cuestionaban las decisiones que se habían tomado en esa reunión.

24 Cybernetworks. 
Gráfico 1. Facebook: número de seguidores de las páginas de grupos, colectivos y organizaciones feministas

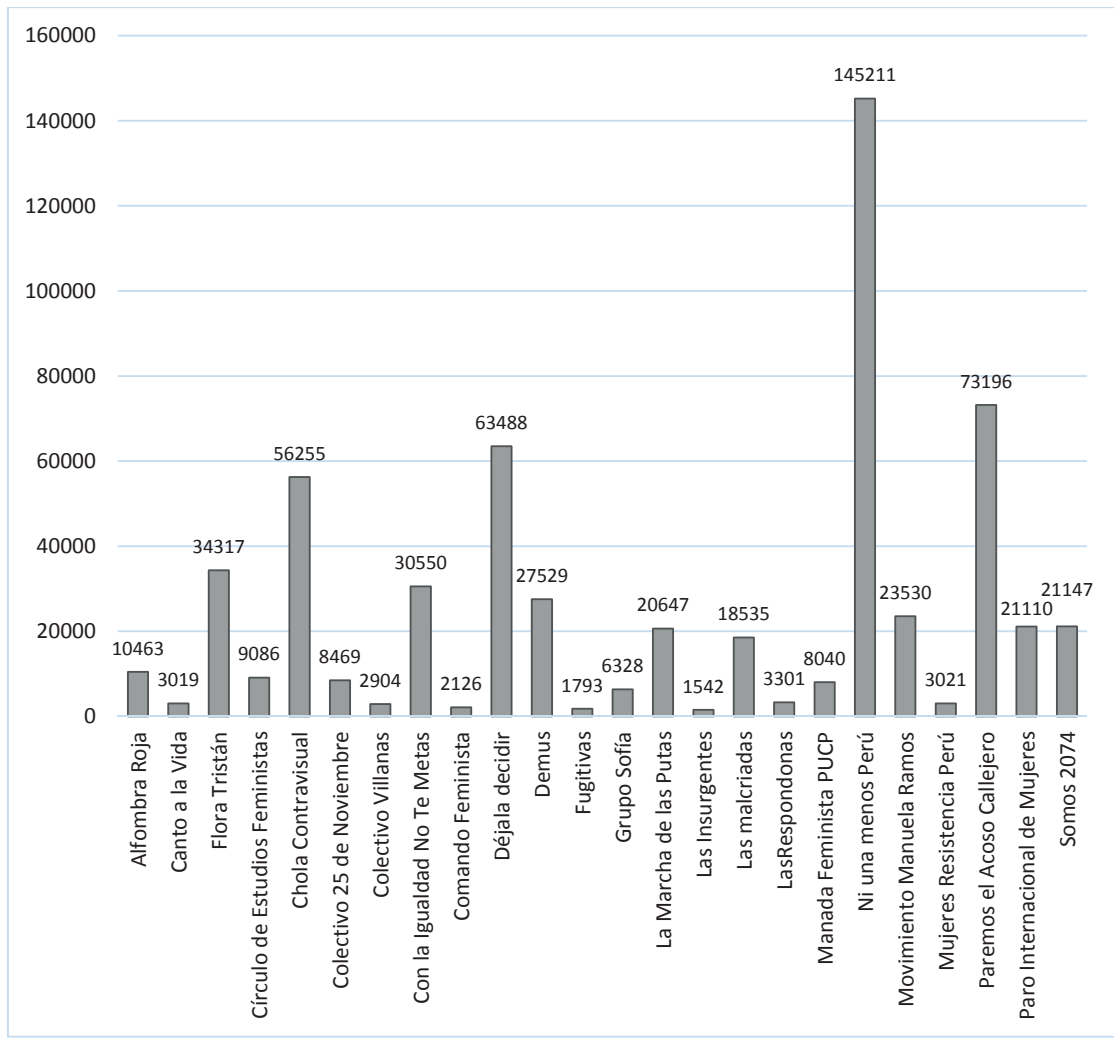

Fuente: Facebook. Elaboración propia.

Fue entonces cuando un grupo de activistas decidió abrir un espacio paralelo de coordinación: las asambleas mujeres. Se trataba de reuniones de convocatoria abierta, organizadas en locales ligados a organizaciones de izquierda, en las que se buscaba tomar acuerdos que involucrasen y representasen -al menos en teoría - a las mujeres en toda su diversidad.

Aunque las asambleas habrían de ser espacios físicos, para hacer la convocatoria de lo que sería la primera asamblea de mujeres se utilizó una herramienta virtual: el fanpage de Facebook de «Mujeres Resistencia», un colectivo feminista ligado a organizaciones políticas de izquierda. La convocatoria fue publicada poco antes de que en el fanpage NUM-TAUTAT se anunciara la marcha del 13 de agosto. 
«Mujeres Resistencia» llamaba a una reunión abierta que se iba a realizar ante la «necesidad de coordinar para garantizar la amplitud, autonomía y organización de la marcha del 13 de agosto ${ }^{25}$. El evento, tal como se puede ver en la figura 5, tendría lugar el viernes 22 de julio, en un local ubicado en el jirón Ica, en el Centro de Lima.

\section{Figura 5}

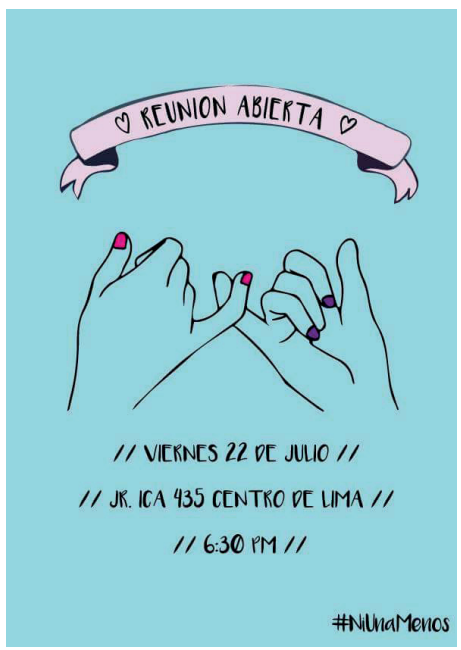

Fuente: Facebook Mujeres Resistencia.

La convocatoria a través de Facebook para la reunión del 22 de julio fue exitosa. Dentro y fuera del local del jirón Ica, había aproximadamente cinco veces más asistentes de los que había habitualmente, cuando se coordinaban ahí las marchas contra la candidatura de Keiko Fujimori. Hubo que trasladar la reunión a otro lugar más grande: el local del partido Patria Roja, también ubicado en el Centro de Lima.

La agenda de aquella primera asamblea fue: (i) apertura de comisiones; (ii) objetivos de la marcha, y (iii) elección de voceras. Sin embargo, no pudieron llegar a acuerdos: desde ese momento, más bien, se abrió una pugna interna en el proceso de organización. De un lado, estaban las mujeres que se habían reunido en casa de Jimena Ledgard y, de otro lado, las que promovían las asambleas de mujeres. Mientras las primeras - entre las que había activistas y no activistas- estaban adscritas en su mayoría a la vertiente feminista del movimiento de mujeres, las segundas provenían de la vertiente política del movimiento de mujeres. Y, como

25 Evento de Facebook creado por Mujeres Resistencia Perú: Recuperado en: https://www. facebook.com/events/515209665345369 
señala Virginia Vargas Valente (2008), los espacios feministas y los espacios políticos tradicionales han mostrado siempre una tendencia a alejarse mutuamente.

Desde entonces, las promotoras de las asambleas de mujeres —a quienes sus antagonistas llamaban las asambleístas - demandaron a las otras - a quienes llamaban la cúpula ${ }^{26}$ - tener acceso a la fanpage NUM-TAUTAT, pero esto no les fue concedido. Las llamadas asambleístas se habían percatado de que un recurso de este alcance era realmente una herramienta potente para convocar a encuentros y difundir la realización de acciones e intervenciones.

En total, se llevaron a cabo tres asambleas de mujeres: el 22 de julio, el miércoles 3 de agosto y el miércoles 10 de agosto. Ninguna de ellas fue anunciada en NUM-TAUTAT. Sin embargo, las asambleístas buscaron otros caminos para difundir sus convocatorias, como lanzarlas desde las fanpage de Facebook de sus propios colectivos, que tenían un alcance muy reducido ${ }^{27}$, o de las fanpage de organizaciones y plataformas políticas y sociales a las que estaban adscritas, como «Keiko no Va» o la Confederación General de Trabajadores del Perú (CGTP).

Entre asamblea y asamblea, se producían reuniones de comisiones de trabajo en espacios físicos. En esos encuentros se repetían las pugnas por el control del fanpage. Jimena Ledgard recuerda un episodio en la Plaza Francia en el que fue directamente emplazada a compartir la administración de la página:

En un momento estas chicas que no conocíamos dijeron: «Entonces ahora tienen que compartir los accesos al fanpage y no sé qué». Entonces yo voy después al grupo y digo: «Miren, están pidiendo esto». Y varias de las chicas dicen: [...] «Aguanta, o sea, ellas están en un montón de colectivos, que manejan sus colectivos como ellas quieren, ¿por qué hay que trabajar con alguien que muchas aquí tienen una historia de agresiones, de desencuentros? ¿Porque vienen a exigirlo? No tiene sentido ${ }^{28}$.

La página NUM-TAUTAT dotó a sus administradoras de cierta institucionalidad. Las personas interesadas en la movilización la veían como la fanpage oficial, lo que otorgaba autoridad y cierto poder a las personas que manejaban esta cuenta. Y ello sucedió en detrimento de las asambleas de mujeres, que en un principio habían sido vistas como espacios legítimos de deliberación. Elizabeth Vallejo, cercana al grupo que administraba la fanpage, lo explica de esta manera:

26 Para más detalles sobre la pugna entre las asambleistas y la cúpula, ver: Caballero Rojas, 2018.

27 Ver el número de seguidores de «Mujeres Resistencia», «Las Insurgentes», «Fugitivas», «Nos pasó en la lucha» en el gráfico 1.

28 Entrevista a Jimena Ledgard, realizada el 12 de setiembre de 2017. 
Tener el fanpage hacía que, como lo manejábamos nosotras, la gente se guiara más de lo que decíamos nosotras que el otro grupo. Pero a la vez la gente también sabía que estaba el otro grupo. La gente pensaba que todo era lo mismo y era una confusión enorme, porque convocaban a asambleas del otro lado y la gente nos reclamaba a nosotras. Nos decían: «Oye, pero ¿por qué cambian lo de la asamblea?». Pero nosotras ni siquiera estamos en la asamblea ${ }^{29}$.

Este tipo de pugnas se prolongó casi hasta el día de la marcha. En la segunda asamblea de mujeres, que se llevó a cabo el miércoles 3 de agosto, se había aprobado que la marcha acabase en la Plaza San Martín, como habían propuesto las asambleistas. Sin embargo, cuando se tramitó el permiso ante la Oficina Nacional de Gobierno Interior (Onagi), la ruta autorizada culminaba en el Paseo de los Héroes Navales, frente a Palacio de Justicia, tal como lo habían acordado semanas antes las mujeres a las que llamaban la cúpula. La ruta de la marcha fue anunciada a través de NUM-TAUTAT.

Elena Mejía, una de las promotoras de las asambleas, recuerda cómo se sintieron ella y sus compañeras cuando conocieron lo que había pasado:

Ahí nos dimos cuenta de que cometimos un gran error al no haber bregado por el fanpage, que era donde se comunicaban todas las decisiones hacia la población. O sea, si tú, por ejemplo, que no ibas a las asambleas, no estabas en ningún grupo de organización, querías saber cuál era la ruta de la marcha, te ibas al fanpage. Entonces el grueso de la movilización iba a hacerle caso al fanpage, pues. Y el fanpage no lo teníamos nosotras, lo tenían ellas. Entonces ese fue uno de los quiebres más grandes y dolorosos que hubo ${ }^{30}$.

\section{REFLEXIÓN FINAL}

Históricamente el surgimiento de la acción colectiva ha requerido la existencia de espacios y canales de comunicación, como rumores, panfletos, asambleas, etc. En la actualidad, las redes sociales digitales también cumplen esta función y lo hacen de manera más efectiva, en la medida que permiten que la comunicación sea más inmediata, alcance a un mayor número de personas y un nivel mayor de interactividad.

En el caso del 13A, hemos identificado cinco etapas en que la red social Facebook y sus aplicaciones y herramientas favorecen el surgimiento de la

29 Entrevista a Elizabeth Vallejo, realizada vía Skype el 17 de setiembre de 2017.

30 Entrevista a Elena Mejía, realizada el 12 de septiembre de 2017. 
acción colectiva: (i) el estallido: es el momento en que las personas expresan y comparten su indignación ante un hecho considerado injusto, en el cual es posible identificar una víctima y un responsable; (ii) el llamado a la acción: es una invocación, no formal ni institucional, a llevar a cabo una acción de protesta; se presenta de manera casi simultánea al estallido y se expresa también a través de las publicaciones del Facebook; (iii) la activación emocional: es el proceso en que las personas empatizan públicamente con las víctimas del acto injusto, adquieren conciencia de la gravedad del problema que se esconde detrás del hecho que generó el estallido y llegan al convencimiento de que la situación es insostenible; los grupos de Facebook o las publicaciones son espacios oportunos para la activación emocional; (iv) organización y coordinación: es el proceso en el cual las personas activadas deciden pasar a la acción y coordinar esfuerzos para llevar a cabo la acción de protesta: el Facebook Messenger resulta bastante útil para estos fines y los grupos de Facebook también pueden serlo; sin embargo, esta etapa requiere que las personas se contacten en el plano físico, no solo en el plano virtual, y (v) información y difusión: es la etapa en la que el grupo encargado de la organización de la acción de protesta mantiene informados a los potenciales manifestantes sobre la movilización a través de canales formales.

Si bien sería arriesgado afirmar que la marcha del 13A fue tan multitudinaria principalmente gracias a Facebook, no debe perderse de vista el potencial de las redes sociales digitales como herramienta para activar emocionalmente a las personas, incluso a aquella ajenas a los activismos, e involucrarlas en episodios de acción colectiva.

\section{REFERENCIAS}

Bard Wigdor, G. y G. C. Artazo (diciembre de 2015). «La maté porque es mía»: feminicidios en la provincia de Córdoba. FLACSO, ed. Revista Latinoamericana de Estudios de Seguridad(17), 67-79.

Caballero Rojas, G. A. (2018). Redes sociales y feminismos en la acción colectiva: el caso de «Ni Una Menos» en el Perú. Lima: Pontificia Universidad Católica del Perú.

Cabral, P. y J. A. Acacio (2016). La violencia de género como problema público. Las movilizaciones por «Ni una menos» en la Argentina. Questión, 1(51).

Carbellido Monzó, C. (5 de febrero de 2018). Grupos de Facebook: qué son, cómo participar y cómo administrar uno. Obtenido de Un Community Manager: https:// www.uncommunitymanager.es/grupos-facebook/ 
Castells, M. (2012). Redes de indignación y esperanza. Los movimientos sociales en la era de Internet. Madrid: Alianza Editorial.

Castro, L. C. (2018). La acción colectiva feminista, ¿de la lucha de clases a la lucha de géneros? Aportes para la comprensión práctica de los movimientos sociales: el caso «Ni Una Menos». Ciencia Política, 13(26), 19-61. https://doi.org/10.15446/ cp.v13n26.67977

Christakis, N. A. y J. H. Fowler (2010). Conectados. El sorprendente poder de las redes sociales y cómo nos afectan. México D.F.: Taurus.

Facebook (2019). Páginas. Obtenido de Facebook: https://web.facebook.com/ help/282489752085908/

Fillieule, O. y D. Tartakowsky (2015). La manifestación: cuando la acción colectiva toma las calles. Buenos Aires: Siglo Veintiuno.

Kadushin, C. (2013). Comprender las redes sociales. Teorías, conceptos y hallazgos. Madrid: Centro de Investigaciones Sociológicas.

Koopmans, R. y D. Rucht (2002). Protest Event Analysis. En B. Klamdermans y S. Staggenborg (eds.), Methods of Social Movement Research (pp. 231-259). Minneapolis: University of Minnesota Press.

Ledgard, J. (16 de julio de 2016). Facebook. Recuperado el 3 de octubre de 2017, de https://www.facebook.com/photo.php?fbid=10153903363859482\&set=a.58856 589481.68530 .501944481

Lin, N. (2002). Social Capital: A Theory of Social Structure and Action. New York: Cambridge University Press.

Neumayer , C. y J. Svensson (2016). Activism and radical politics in the digital age: Towards a typology. Convergence, 22(2), 131-146. https://doi. org/10.1177/1354856514553395

Ostrom, E., T. K. Ahn y C. Olivares (2003). Una perspectiva del capital social desde las Ciencias Sociales: capital social y acción colectiva. Revista Mexicana de Sociología, 65(1), 155-233.

Piñeiro, R. y F. Rosenblatt (2017). Tipos de activistas en organizaciones partidarias. Politica y gobierno, XXIV(2), 275-300.

Tarrow, S. G. (2012). El poder en movimiento. Los movimientos sociales, la acción colectiva y la política. Madrid: Alianza Editorial.

Vargas Valente, V. (2008). Feminismos en América Latina. Su aporte a la política y a la democracia. Lima: Universidad Nacional Mayor de San Marcos. 